\title{
QUEEN'S
QNIVERSITY
BELFAST
}

\section{Regional variations in care planning in Northern Ireland: Proposing an ecological model of decision-making}

Fargas, M., \& McSherry, D. (2020). Regional variations in care planning in Northern Ireland: Proposing an ecological model of decision-making. Qualitative Social Work, 19(2), 229-245.

https://doi.org/10.1177/1473325018811474

Published in:

Qualitative Social Work

Document Version:

Peer reviewed version

Queen's University Belfast - Research Portal:

Link to publication record in Queen's University Belfast Research Portal

Publisher rights

Copyright 2018 SAGE. This work is made available online in accordance with the publisher's policies. Please refer to any applicable terms of use of the publisher.

\section{General rights}

Copyright for the publications made accessible via the Queen's University Belfast Research Portal is retained by the author(s) and / or other copyright owners and it is a condition of accessing these publications that users recognise and abide by the legal requirements associated with these rights.

Take down policy

The Research Portal is Queen's institutional repository that provides access to Queen's research output. Every effort has been made to ensure that content in the Research Portal does not infringe any person's rights, or applicable UK laws. If you discover content in the Research Portal that you believe breaches copyright or violates any law, please contact openaccess@qub.ac.uk. 


\title{
Regional variations in care planning in Northern Ireland: Proposing an ecological model of decision-making
}

\author{
Montserrat Fargas-Malet, School of Social Sciences, Education and Social Work, Queen's \\ University Belfast
}

Dominic McSherry, School of Social Sciences, Education and Social Work, Queen's University Belfast

Care planning for children who enter care can be influenced by a range of factors. In Northern Ireland, there are differences in the proportions of children in different types of placements across the five Health and Social Care (HSC) Trusts (equivalent to local authorities in England and Wales). The aim of the study was to identify the reasons for these differences. In order to do that, focus groups in each of the Trusts were conducted with social work professionals involved in care planning. Based on the study findings, an ecological model of decision-making in care planning is postulated. Differences among all of the Trusts were found within the model's three levels, despite all of the Trusts operating under the same broad policy framework for care planning. For instance, different mindsets were evident, as participants in some of the Trusts clearly equated the notion that children should be provided with a permanent home with adoption, while in focus groups in other Trusts, this mindset did not prevail. In addition, the Trust structures and initiatives differed slightly and there were differences in the global context factors influencing decision-making. Based on these findings, we believe regional practical guidance and policies should be developed collectively by the five Trusts, so as to avoid the possibility of children facing a postcode lottery regarding the placements offered to them.

\section{Introduction}

Worldwide, when children are being abused or neglected or considered at risk, decisions are made whether or not to remove them from the care of their birth parents, and about 
alternative placement. Within the UK, most of the children who are removed return to their birth parents within a year. For some children, however, rehabilitation to their birth parents is not considered possible. In these instances, long-term placements are sought, including long-term foster and kinship foster care, care under private law orders (i.e. a Special Guardianship Order or a Residence Order), and adoption. These are crucial decisions that may impact on the future short and long-term wellbeing of the children and their families (Benbenishty et al., 2015). This article focuses on possible reasons for differences in care planning decisions between different regions, Health and Social Care Trusts, in Northern Ireland.

\section{Regional Variations}

International research and official statistics indicate that regional variations exist in relation to the type of long-term placement identified for children in care. McSherry and colleagues (2010) found a significant relationship between children's care pathways and the region in Northern Ireland where they lived. Similarly, a study in England (comprising seven local authorities) found that the pathways of 3,872 maltreated children (whether they returned home, remained in care or were adopted) differed significantly by local authority, even when children's characteristics and histories were taken into account (Biehal et al., 2015). A range of factors have been identified across a number of studies (Bebbington and Miles, 1989;

Dickens et al., 2007; Oliver et al., 2001; Packman and Hall, 1998; Statham et al., 2002) that appear to contribute to this variation. These include: levels of underlying need and deprivation in a particular area; level of staff turnover; resource and staffing levels; technical difficulties (e.g. problems with data-management systems); departmental policies and operational factors (e.g. availability of family support services and decision-making procedures); the underlying ethos and wider culture of the department; and beliefs and attitudes of individual staff members.

This is an important issue for two reasons. First, because all children entering the care system, irrespective of their background, should be treated equally and in a consistent way, 
with the identification of long-term placement based upon the child's needs, not local placement dynamics. Second, international research indicates that there may be differences in quality of life outcomes for children who either return home from care to their birth parents, remain in foster and kinship foster care on a long-term basis, or are adopted from care. This raises concerns about the extent to which placement practice at a local level may impact upon children's long-term wellbeing.

\section{Long-term placement outcomes}

Placement types (i.e. adoption, foster care, kinship foster care, guardianship orders / residence orders, residential care, and reunification with birth parents) have been compared in many studies in relation to a range of outcomes (e.g. stability, education, mental and physical health, attachment/belonging, socio-economic long-term outcomes, etc.). In general, adopted children and young people have been found to display better outcomes than those living in care (e.g. Lloyd and Barth, 2011; Vinnerljung and Hjern, 2011). Kinship and non-kinship care has also been compared, with kinship being found to also provide better outcomes (Winokur et al., 2015). Residential care has been found to be the placement with the poorest outcomes compared to other placements (e.g. Ford et al., 2007; McSherry et al., 2015). Reunification of children in care has been the focus of some studies in which it has been contrasted with remaining in care, with the latter appearing to lead to better outcomes (e.g. Biehal et al. 2015; McClung and Gayle, 2010; McSherry et al., 2013). However, all these outcomes have been found to be also influenced by a range of other factors, such as placement stability, childhood adversity prior to care, and age of the child at placement (e.g. Luke and O'Higgins, 2018; McSherry et al., 2016; Stott and Gustavsson, 2010). In terms of achieving placement stability, having adequate supports for each placement either at home (with birth parents) or out-of-home (in foster care) appears to be crucial for positive outcomes (e.g. Goemans et al., 2018; Rock et al., 2015).

The purpose of this article is not to establish what placement types should be favoured over others. We understand that the context and circumstances of each child are different, and 
that a variety of pre-care, in-care and post-care factors need to be taken into account in each case. As Hambrick, Brawner and Perry (2018: 105) argue, the 'heterogeneity in developmental history and current functioning of youth makes blanket policies regarding placement unwise'. However, we believe that it is still important to address withincountry/regional differences in practice, as any variation in practice may raise important ethical issues, particularly in terms of equality of treatment and opportunity for vulnerable children.

\section{Northern Ireland context}

The legal framework in Northern Ireland provides Health and Social Care (HSC) Trusts (equivalent to local authorities in Great Britain) with a duty to investigate when it is believed that a child is suffering or likely to suffer significant harm (Children Order 1995, Article 66); and it allows them to share parental responsibility with the parents through a Care or Supervision Order (Article 50), a Child Assessment Order (Article 62), and an Emergency Protection Order (Article 63). In some cases, children are then removed from their parents, and placed into either kinship foster care, non-kinship foster care, or residential care (primarily for teenagers). However, in some cases, children remain living with their birth parents while the Trust makes an application for a Care Order, and on some occasions thereafter, even when a Care Order is granted. A child can also be accommodated by a Trust on a voluntary basis, with birth parents retaining full parental responsibility and being able to resume care of their child at any time. Children may remain in kinship and nonkinship foster care for a short period of time before returning to live with their birth parents, or on a long-term basis, if the risks to their welfare at home remain. In cases where children are deemed unlikely to be able to return to their birth parents, adoption can be pursued, where birth parents lose their parental responsibility for the child.

In the UK, both birth parents normally have to consent to the adoption, unless they cannot be found, they are deemed incapable of giving consent, or if it is in the child's care plan and the Court agrees that adoption is required and is in the child's best interests. In some 
instances, kinship and non-kinship foster carers might apply to have the Care Order superseded by a Residence Order (Children Order 1995, Article 8), which takes the child out of the care system and gives the carers shared parental responsibility with the birth parents.

Decision-making theories in social work

Decision-making theories have been inclined to focus on individual factors rather than the social context and the broader environment. Within the field of social work, a variety of theories have been used to make sense of professionals' judgement and decision-making processes, and different authors have discussed this dichotomy (i.e. individual agency versus structure/context), as well as describing a series of approaches going from more prescriptive (based on how a rational individual should act) through to those more descriptive (based on how individuals make decisions in real life) (Taylor, 2012). While social work researchers have described rational actor theoretical frameworks, most acknowledge the importance of social context (Keddell, 2014).

Van de Luitgaarden (2009) described the rational choice approach and introduced the principles of recognition-primed decision-making. The first approach focuses on weighing the costs, risk and benefits of the identified options using statistical methods. It is a prescriptive model because it prescribes a particular 'right' way to take 'rational' decisions. It is also normative because it seeks to find out the ways in which decisions are taken in relation to the way in which they should be taken. It was thus argued that such an approach did not actually work that well in the field of social work practice, because of the 'subjective, relative and debatable' nature of the situation or problem (and the ambiguous, conflicting, inaccurate and incomplete information available) that social workers tend to have to grapple with. In contrast, the recognition-primed approach recognises the context of real-life settings and focuses on assessing situations rather than the deliberation over choices. Similarly, Taylor (2017) used a psycho-social rationality model to make sense of social workers' judgement. 
This approach considers both the decision context as well as the cognitive processes of the individual making the decision.

Many researchers have proposed ecological models of decision-making within social work practice. For instance, Font and Maguire-Jack (2015) used Baumann et al.'s (2011) Decision-Making Ecology (DME) framework in their study of decision-making in child protection. The DME framework suggests that decisions are influenced by factors related to the individual case; the specific agency (e.g. their policies and procedures, time and resources, organisational culture); the individual decision-maker (e.g. training, background, experiences, attitudes); and external factors (e.g. laws and attitudes, socio-economic elements). Helm and Roesch-March (2017) also proposed an ecological model of professional judgement. The model originated in the concepts of ecological rationality and systems thinking, and integrated micro systems and meso systems with the macro system. Key components of this ecology included individual judgement/decision-making (using a range of cognitive approaches, including intuitive and analytical thinking); judgement and decision-making in teams and groups (the dynamics of group decision-making); and judgement and decision-making in organisational systems (including the culture of the organisation, group and/or team). In this paper, supported by the study findings reported in the results section, an ecological model of decision-making is introduced in order to identify factors that may explain regional differences in care planning.

\section{Method}

The study reported in this article used a catch-up retrospective longitudinal design (Robins, 1978), and was conducted in two parts. In Part 1 of the study, a sample of children who had a Care Order made between 1st April 2006 and 31st March 2008 were identified, and their social work case files were reviewed retrospectively (four to six years after the making of the Order). Social work reports to Court were also analysed in order to identify the key reasons for the making of the Care Order. We also analysed the care plan endorsed on the day the Care Orders were made, in order to identify the specified long-term placement for each 
child/young person. Reviewing the social work case files also allowed us to identify the current placement of each child/young person. Where this information was not available from the files, it was sought directly from the Trusts. Statistics provided directly to the research team by the Northern Ireland Guardian ad Litem Agency (NIGALA) indicated that 234 Care Orders were made between 1st April 2006 and 31st March 2008 in respect of 401 children/young people. Consent was obtained to review social work case files for 72 Care Orders (31\%). In Part 2, focus group interviews were conducted with senior managers in each of the HSC Trusts. This article focuses on these interviews.

\section{Ethical approval}

The Office for Research Ethics Committees Northern Ireland (ORECNI) granted ethical approval for the study, and research governance approval was granted by all five HSC Trusts across Northern Ireland. All participants in the focus groups were provided with an information sheet about the study and were required to sign a consent form before participating.

Sample

Focus group interviews were conducted with senior managers in each of the five Health and Social Care Trusts. We asked the HSC Trusts to identify senior managers with a particular role in care planning. These were then identified by the Trusts themselves, and focus groups arranged by them. Participants included: Chairs of Looked After Children (LAC) reviews and permanency (best interest) panel meetings; Children's Services Managers; and Assistant Directors for Children and Family Services. Within the UK, children in care are formally referred to as Looked After Children (LAC). The LAC Reviews are statutory reviews of the child's progress across a range of domains, including health and education. Permanency panel meetings occur to assess how a child's need for permanency, or a placement through to the end of childhood, is being met, and action decisions to achieve such accordingly. 
Within this article, the names of the five Health and Social Care Trusts in Northern Ireland have been anonymised and given random letters to distinguish each one, so reference will be made to Trust A, Trust B, Trust C, Trust D and Trust E. The five HSC Trusts provide integrated health and social care services across Northern Ireland, providing a wide range of health and social care services to the community. Table 1 provides statistical information for each Trust.

Table 1: Information on each HSC Trust

\begin{tabular}{|l|l|l|l|l|l|}
\hline & Trust A & Trust B & Trust C & Trust D & Trust E $^{9}$ \\
\hline Total population & 463,297 & 300,000 & 340,000 & 345,000 & 365,712 \\
\hline Geographical area ${ }^{1}$ & 1,733 & 1,869 & NK $^{5}$ & NK $^{7}$ & NK \\
\hline Looked After Children $^{2}$ & $59.5^{3}$ & 80.1 & $97.6^{6}$ & $64.3^{8}$ & 50.3 \\
\hline Child Protection Register $^{2}$ & 42.2 & 48.9 & 45.6 & 47.9 & 60.2 \\
\hline
\end{tabular}

${ }^{1}$ Square miles

${ }^{2}$ per 10,000 child population (as of $31 / 3 / 2017$ )

${ }^{3} 203$ of them are in kinship foster care and 304 in non-kinship foster care

${ }^{4}$ Most of this area is rural, and $82 \%$ of its LAC are placed in foster homes, and $53 \%$ of foster placements are kinship. Trust B saw a growth of foster placements that are kinship from $26 \%$ to $53 \%$ between 2011 and 2017.

${ }^{5}$ Not known, but Trust $C$ is the smallest in terms of geographical area and the most densely populated. It contains some of the most deprived areas in Northern Ireland.

${ }^{6}$ Trust $C$ has the highest number of children in residential care $(n=44)$ and the highest proportion of LAC being placed with a parent (16\%) than in any other Trust.

${ }^{7}$ Not known, but Trust $D$ is the second smallest in terms of geographical area.

${ }^{8}$ Trust $D$ has the lowest proportion of foster placements that are kinship placements (39\%)

${ }^{9}$ Central and Eastern European migration comprises $4.2 \%$ of the Trust E population, doubling the Northern Ireland average. It has the lowest number of kinship placements $(n=153)$.

\section{Data collection}

Focus groups have regularly been used in social work research for multiple purposes, including understanding decision-making processes (Linhorst, 2002). In this study, focus 
groups involved the use of a three part interview schedule. In the first part, participants were asked to discuss the underlying Trust philosophy and organisational culture regarding the long-term placement of children in care. They were also asked to examine the role that they believed other factors played in the placement patterns evident within their Trust, such as: the availability of resources; socio-geographic issues; and their relationship with the Courts. In the second part, they were introduced to a vignette (hypothetical case study), and asked to discuss a series of questions regarding the decisions they would take. In the last part, they were shown the study Part 1 findings. They were asked to comment on the particular placement patterns evidenced in their own Trust. However, this article only focuses on the first part.

Five focus group interviews were conducted (one in each Trust), each lasting approximately one hour, with a minimum of three participants in each group. The data was recorded using a digital recorder with permission. Participants had been given an information sheet and completed and signed a consent form before the start of the interview.

\section{Analysis}

The focus groups were digitally recorded and transcribed verbatim. The transcripts were analysed using a thematic framework approach (Ritchie and Spencer, 1994). This involved a five step process: familiarisation, identifying a thematic framework, indexing, charting, and mapping and interpretation. During the familiarisation stage, the two researchers in the study read a few times the transcripts. Although they were open to new themes emerging, as the research was designed around a priori issues, these issues essentially guided the thematic framework. Indexing involved identifying sections of the data corresponding to a particular theme. During the charting stage, the previously indexed fragments of data were input in Excel, to be arranged in charts of the themes. In the Excel file, the headings and subheadings drawn during the thematic framework constituted the columns, and the cases (i.e. each focus group) were represented in the rows, with the data being placed in the 
corresponding cells. The final stage, mapping and interpretation, concerned the analysis of the main characteristics as shown in the charts.

\section{Results}

\section{Care planning in the Northern Ireland Health and Social Care Trusts}

When asked about the HSC Trust's underlying philosophy regarding care planning, focus group participants frequently mentioned the concepts of permanence and stability. In all of the Trusts, they made reference to broad regional policy principles, which followed the Children Order 1995 philosophy and regional policy and procedures documents, i.e. first trying to place children with their parents, and if not possible, with other family members, and if not feasible, securing permanency in other long-term placements.

However, despite this general approach, there were slight differences among Trusts in terms of focus in their general practice. For instance, practitioners in specific HSC Trusts, i.e. Trusts A, D and E, expressed a clear focus on adoption as the main permanent type of placement, when rehabilitation or family were ruled out, and especially in cases of young children. Participants in these focus groups talked about their care planning systems or approaches, which were labelled "parallel planning system" in Trust A, and "concurrent planning", or "twin track/triple track plans" in Trust D and Trust E, but also in Trust A. Although they were given slightly different names, it was largely the same approach, i.e. considering different plans at the same time, for example fostering with a view to adoption, or fostering with a possible return to birth parents or adoption by the foster carers both considered as possible outcomes.

However, participants from these three Trusts differed in their explanations of how this general system was carried out. Thus, participants in Trust D claimed that their Trust was the only one to have a permanence team, focused exclusively on advancing adoption care plans in a timely manner. They were also seeing a big drive over the past two to four years to get safeguarding practitioners to present at the permanence panel as early as possible; 
and an increasingly high number of children were transferring into the permanence team, especially in the previous six months. Meanwhile, participants in Trust A explained how the permanence policy in the Trust included an instruction that adoption be considered after 12 weeks of the child becoming Looked After, at their first LAC review. In addition, in that same Trust, focus group participants claimed that their Trust was the only one using concurrent placements. Concurrent placements mean that children are placed with concurrent carers, and they will either move back to their parents or they will remain in that placement and be adopted by those carers.

In Trust E, participants explained that they were in the process of starting to use concurrent placements through the Home in Time project, and they were beginning to recruit concurrent carers. In addition, in Trust A, D and E, they used dual approved carers. Dual approved carers are used when rehabilitation has been ruled out but before children are freed for adoption (a precursor to adoption, where full parental authority is transferred to the HSC Trust, before final transfer to adoptive parents when an Adoption Order is made).

Many participants mentioned age as a crucial factor in whether adoption was pursued as a care plan or barely considered. In fact, in Trust A, according to the focus group participants, concurrent placements were typically used with babies and young children entering care. Participants in Trust E explained the reasons behind a focus on adoption for babies and younger children, which had to do with the children's established relationships:

... those [younger children] are the age group that are more likely to go towards adoption, and the timing of that is important because the closer they come to the eight, nine age group, they have established family connections, there are much more difficulties in terms of their loyalties, in terms of them committing to a new mother and father, when they very clearly know their own identity, and maybe you are going to have to have a very high level of contact with their own parents. So that's why the focus is on that young age group, and the younger that is achieved the much better outcomes for the child. 
Participants in most of the Trusts, even those where there appeared to be less of a focus in adoption, claimed that there had been an increase of adoption care plans, and adoption figures in recent times:

... our figures of the past 18 months have rocketed over adoption. (Participant in Trust B)

Participants in Trust B believed that in the past, they had the lowest adoption figures in the region because of their greater focus on family support. On the other hand, participants in Trust $\mathrm{C}$ believed their Trust was experiencing particular challenges in promoting adoption as a placement option for Looked After children. According to these participants, these barriers or difficulties were:

1. Adoption was believed to be more highly contested in Trust $C$ than in other Trusts, which caused delay, where 'child ages out', and where there would then be a lesser inclination to break attachments and risk another move;

2. Adoption was claimed to be knocked by certain individuals in the adoption panel, who did not feel child was 'perfect enough' to be adopted;

3. There was an inability to find adopters, where the Court focused on culture (e.g. 'finding a black family for a black child');

4. There was a reluctance to make Orders because of the perception that it invited an appeal by the parent.

Despite these difficulties, they identified a tendency within their Trust to approach foster carers about adoption. Although participants recognised the benefits of adoption, participants in Trust A also stressed the need for supports to be in place for adoptive placements, acknowledging the complex needs that those children had:

... unless you support it, you're going to end up very costly when they reach teenage years. 
They also explained that nine percent of LAC Therapeutic Services' overall time was dedicated to adoption. Participants in Trust B also recognised the need for supports for adoptive placements, and claimed that their Trust was championing a social care model of post-adoption support, which was intentionally different from the clinical model (adopted by other Trusts), and involved a skilled therapist delivering this model. It entailed training other staff, looking at the dynamics within the families, and applying family therapy techniques to keep families together.

\section{Influencing factors in care planning and care placement profiles}

Focus groups participants described a range of external and internal influences and pressures on care planning, which included: relationship with the Courts; the sectarian divide; socio-economic issues, particularly in terms of levels of deprivation and endemic poverty; lack of resources; and demographic and cultural issues of the population in the respective Trusts.

Relationship with the Courts: Participants in all the focus groups were asked to describe their relationship with the Courts. Although participants in Trusts A, E and D claimed that there was some variability among the different Courts and judges, three main issues were raised by participants in different Trusts. These were: 1) focus on parents' rights and disregard for children's rights; 2) a rise in the use of independent assessments and independent experts; and 3) substantial disagreements with the Courts. These issues have featured in other studies in the UK (Beckett et al., 2007; Davidson and McKenzie, 2010; Ward et al., 2006). In relation to the first point, participants in Trust $B$ and $C$ argued that the Courts tended to favour the human rights of parents, and the child was often lost in the rulings. In relation to the second point, participants in Trust $E$ argued that social workers were not seen as experts or as independent practitioners within the court arena. This same issue has been reported in another study in England (O'Connor and Leonard, 2014), which highlighted the greater power and status that legal and medical professionals had compared to social work 
professionals, especially in Court. Similarly, participants in Trust A claimed that the quality of social work reports were not acknowledged, with some judges being particularly dismissive towards social workers. It was felt that this caused difficulties when dealing with parents. As a result, according to participants in Trust E, there was a focus on having an expert witness or an independent social worker to do an assessment, although these assessments rarely contributed anything more than what was already presented in the social work report to Court. Participants in Trust E and Trust B stated that expert assessments were costly and caused unnecessary delay for children to achieve security and stability. Hence, participants in Trust B explained that it takes an average of three years or more in Northern Ireland for a child to be adopted, compared to two years or less in England. Besides, Davidson and McKenzie (2010) found that waiting for an expert assessment was the most commonly identified factor influencing care planning in a particular local council in Scotland.

Finally, in relation to the last point, a range of disagreements with the Courts were reported by participants in Trusts B, D and E. For participants in Trust E, one common disagreement was the discharge of Care Orders when children return home, as there had been a decrease in the numbers of children at home on full Care Orders. The children were instead returned home subject to Interim Care Orders, which were discharged at final hearing or replaced by lesser Orders. This was because the Trust tried to avoid having children at home subject to full Care Orders, despite the fact that the Courts often did not allow them to discharge the Care Order. For participants in Trust D, a common dispute was the high level of contact for children with a care plan of long-term foster care. While participants in Trust E argued that the Court's approach was impacting particular decisions, with less confident social workers being sometimes less inclined to go to Court to fight particular battles such as contact, participants in Trusts A and B felt that the Trust social workers were still robustly putting forward their views, and were able to stand over their assessments:

You are trying to deal with how this child's been neglected, abuse or whatever the particular set of circumstance, and all you are hearing is 'have you considered the human 
rights of the parents and gave due consideration to this person's culture?' it takes over the case, and the child is gone completely. (Participant in Trust C)

We have created a whole industry around courts about independent assessments, independent experts, and not necessarily good for children in terms of time lines, in terms of creating that security and stability. (Participant in Trust B)

We have had several instances where we have tried to discharge the Care Order and the courts don't allow us... there is a wee bit of the court using the Care Order as a means of controlling the Trust. (Participant in Trust E)

Sectarian divide: This factor was mentioned by participants in Trusts $C$ and D. Northern Ireland is emerging from a political conflict, and is still a divided society, particularly in some areas. In Trust C, this issue was related to the refusal of parents to use services located in the "other" community area, which was a stumbling block to getting assessments completed, causing delay. In Trust D, participants talked about the difficulties it caused in terms of matching children with placements:

When you're doing the matching of children with foster placements, that's one of the factors you have to take into account of, because you're not going to put a child from a nationalist background in a predominantly loyalist area, because you're increasing the child's vulnerability. ... our placements are limited with regards to our adolescents, so some of them are placed in communities where their background is entirely different, which we acknowledge... but you're limited again with regards to resources.

Social economic issues: This was mentioned by participants in Trust B and C. Participants in Trust B explained that the endemic rural poverty in their Trust, coupled with the economic downturn, had impacted on the ability of carers to take on Residence Orders. Thus, according to them, kinship carers were particularly weary of taking Residence Orders for fear of losing supports. Similarly, participants in Trust $C$ talked about kinship placements being 
located in high deprivation areas, which meant they were very much reliant on financial supports.

Lack of resources: Participants in Trust B identified the impact of having to deal with cuts as a factor that could have an influence on decision-making. They argued that due to austerity policies, there was an emphasis on "cost value and efficiency" and a drive to getting children out of the care system. Participants in Trusts D and E also mentioned resources and recruitment of carers. Participants in Trust E identified the ability to recruit enough carers as a challenge in the Trust, and suggested that there is more reliance on kinship carers in an urban Trust than there is in a rural one:

If you are in an urban Trust you are not going to have the resources of fostering population that you would have of a more rural one, that's the reality.

Population factors: Participants in Trust E explained that there was a significant black minority ethnic population (BME) (or foreign nationals) in the Trust (see Table 1), which was overrepresented in their LAC statistics. They felt that this brought a series of considerable challenges, including: the difficulty of placing children in their own cultural background; no or little possibility for kinship placements, with an additional inability to secure contact, due to no extended family available; and challenges to acquiring a detailed family history.

\section{Discussion: An ecological model}

Based on the findings reported in this article, we propose an ecological model of decisionmaking in care planning, similar to the ecological models described in the introduction. This model, as depicted in Figure 1, is descriptive rather than prescriptive. Thus, it enables us to explore the factors that may lead to regional differences in care plans, when the characteristics of the individual case/child/family (e.g. age of the child, family histories, siblings, etc.) are the same. In this model, decision-making regarding care planning in each of the Trusts is partly influenced by three different kinds of factors: 
- Individual and team factors, which would include the social workers' individual and group judgements, their practice mindsets (i.e. sets of assumptions or understandings held by an individual or group), and confidence defending their decisions;

- Regional practice factors, which would include local practices, structures, resources, projects, guidelines, initiatives, and policy frameworks; and

- Global context factors, which would include social workers' relationship and dynamics with the Courts, other professional's mindsets, as well as the socioeconomic and cultural context of each HSC Trust (e.g. sectarian divide, poverty, migration, etc.).

\section{Figure 1: Ecological model of decision-making in care planning}

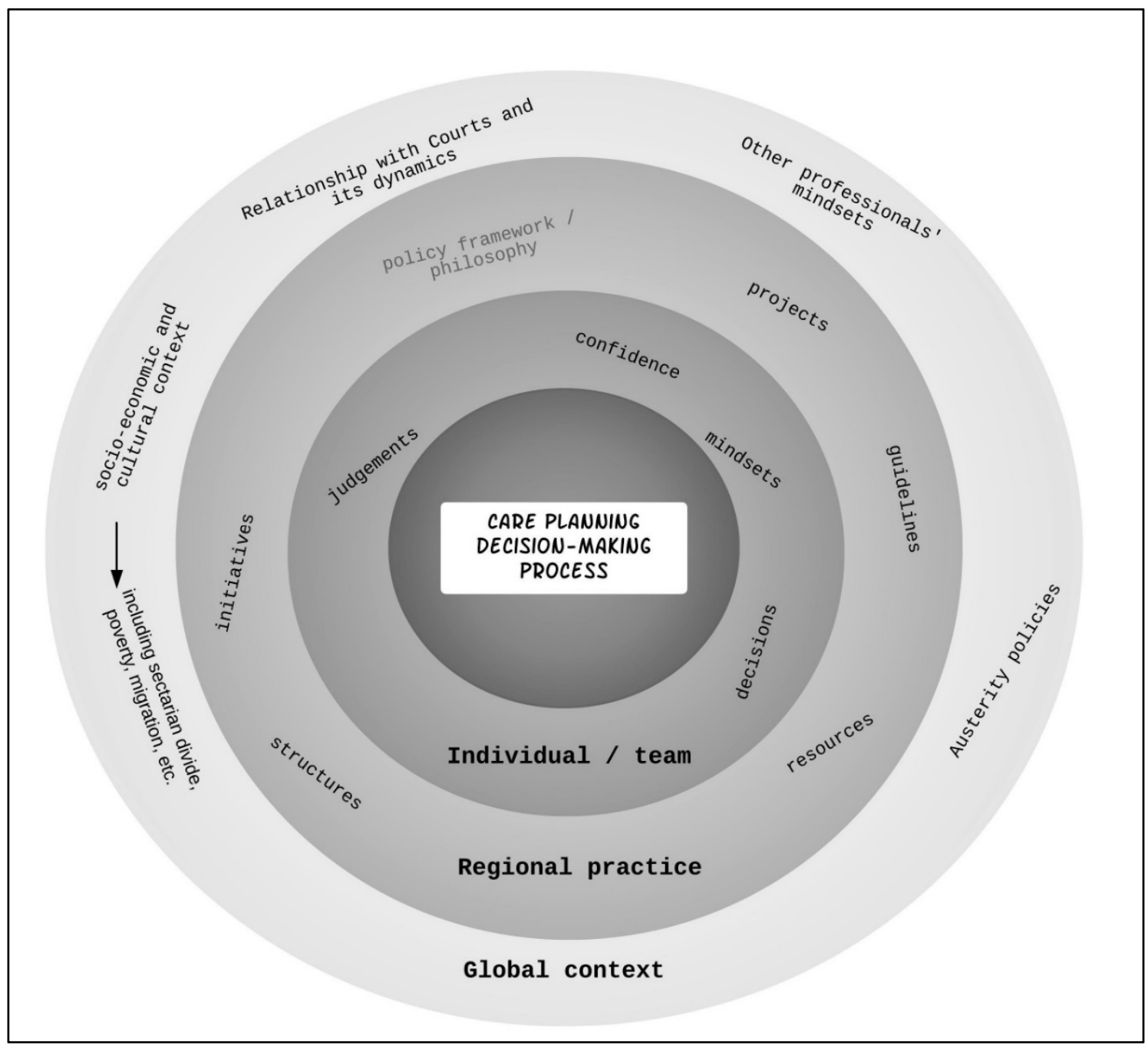


Regarding individual and team factors, one of the main points that was highlighted was the confidence of social workers (which often depended on their experience) to stand by their assessments in Court. While participants in Trust A and B argued that social workers were confident in putting forward their views, participants in Trust E felt that some social workers were not confident enough to fight battles such as contact. Participants in different Trust also talked about specific mindsets (e.g. children have to be "perfect enough" to be adopted, in Trust C) within their organisation that influenced the type of placement that was favoured for particular children.

Regarding regional practice factors, several factors were revealed. In terms of policy frameworks, all the participants referred to permanence and stability and followed the broad regional policy principles, although practices, structures and Trust guidelines appeared to differ. For instance, Trust $D$ participants mentioned the existence of a permanence team (which they argued did not exist in the other Trusts), and Trust A participants talked about their permanence policy that instructed them to mention adoption in the children's first LAC review, as well as their concurrent placements (which they believed did not exist in the other Trusts). Meanwhile, Trust C participants highlighted their family support projects.

Finally regarding global context factors, participants in most HSC Trusts referred to the difficult relationship they held with the Courts, particularly in terms of substantial disagreements and a rise in the use of independent experts and their assessments. Socioeconomic and cultural factors also featured heavily, particularly when trying to place children (i.e. poverty levels, numbers of ethnic minorities, and sectarian divide).

Thus, the use of focus groups proved useful in revealing the complexity of care planning across the five Health and Social Care Trusts in Northern Ireland. Taking into account this model, only the policy framework or philosophy regarding care planning was the same across Northern Ireland, but most of the other factors appeared to differ to some degree. For instance, judging by the reflections of the focus groups participants, three of the HSC Trusts (A, D and E) had a clear adoption focus, which was apparent and consistent in their 
mindsets, practices, initiatives and Trust guidelines, while this was not particularly noticeable in Trust B and C.

There were obvious limitations to the study, in that only a small number of practitioners in each HSC Trust took part, thus having implications for the generalisability of its conclusions. However, the practitioners that took part had leading roles in this area of work. Further focus groups with fieldwork social workers would enhance the study.

\section{Conclusions}

The focus groups in this study enabled us to explore how the views of senior practitioners operated within a particular context, and facilitated the development of an ecological model to understand regional variation in decision-making. Within the context of Northern Ireland Health and Social Care Trusts, decision-making processes in care planning appeared to be considerably influenced by factors within the three different levels (individual and team, regional, and global) identified, including the austerity situation with its cuts to public services, the Courts and their own influences and practices, the characteristics of the population within each HSC Trust, such as poverty levels, minority ethnic population, the sectarian divide, etc. Previous research has already provided evidence of the complex interplay between organisational processes and resources and subjective dimensions in decision-making in children and families social work (O'Connor and Leonard, 2014). This study reinforces these findings within the particular setting of care planning in Northern Ireland. In addition, our findings suggest that even within the smallest region of the UK, there can still be geographic variations in decision-making and care planning. This may lead to a "postcode lottery" for children who enter care, which could partly be a result of the Trust's differing mindsets, organisational cultures and practices, their geographical and social realities, and their resources.

Although the article does not directly address the debate regarding the merits of different types of long-term placement, which has been addressed in other work (McSherry et al., 
2016), on the basis of the UN Convention on the Rights of the Child (UNCRC), children should have the same opportunities, and any postcode lottery regarding children's placements should be considered an infringement of these rights. As Keddell (2014) argues, despite the complexity of environmental and cognitive factors that influence these decisions and cause these variations within the same country, we should find ways to establish consistent direct guidance and decision systems. Thus, we argue that a regional policy and guidance document should be developed and implemented in collaboration between the five HSC Trusts in Northern Ireland. These policies should take into account best practice in each of the HSC Trusts. Thus, the range of support projects and current local policies available in each area need to be carefully assessed in order to either be dismissed/redesigned or expanded to the rest of Trusts in view of the available evidence.

In doing so, it would also be critically important to be mindful of the differing socio-economic and cultural characteristics of each area, especially in terms of poverty, ethnic minority population and sectarian division/conflict. This may allow for a more efficient targeting of resources at the Departmental level to areas of particular need in Northern Ireland, thus enabling a more balanced system across the different Trusts to emerge. This collaborative process should be one that all Trusts engaged in, each gaining by learning from each other in terms of best practice, and all highlighting to Government their areas of greatest need. Governments have particularly responsibilities when it comes to meeting UNCRC obligations.

\section{References}

Baumann D, Dalgeish L, Fluke J and Kern H (2011) The Decision-Making Ecology. Washington, DC: American Humane Association.

Bebbington AC and Miles JB (1989) The background of children who enter local authority care. British Journal of Social Work 19: 349-368. 
Beckett C, McKeigue B and Taylor H (2007) Coming to conclusions: social workers' perceptions of the decision-making process in care proceedings. Child \& Family Social Work 12(1): 54-63.

Benbenishty R, Davidson-Arad B, López M, Devaney J, Spratt T, Koopmans C, Knorth EJ, Witteman CL, Del Valle JF and Hayes D (2015) Decision making in child protection: An international comparative study on maltreatment substantiation, risk assessment and interventions recommendations, and the role of professionals' child welfare attitudes. Child abuse \& neglect 49: 63-75.

Biehal N, Sinclair I and Wade J (2015) Reunifying abused or neglected children: Decisionmaking and outcomes. Child Abuse and Neglect 49: 107-118.

Davidson $L$ and McKenzie K (2010) An examination of the factors that facilitate and hinder the care planning process for very young children in Scotland. Adoption \& Fostering 34(1): 33-40.

Dickens J, Howell D, Thoburn J and Schofield G. (2007) Children starting to be looked after by local authorities in England: an analysis of inter-authority variation and case-centred decision making. British Journal of Social Work 37(4): 597-617.

Font SA and Maguire-Jack K (2015) Decision-making in Child Protective Services: Influences at multiple levels of the social ecology. Child Abuse and Neglect 47: 70-82.

Ford T, Vostanis P, Meltzer H and Goodman R (2007) Psychiatric disorder among British children looked after by local authorities: comparison with children living in private households. The British Journal of Psychiatry 190(4): 319-325.

Goemans A, van Geel M and Vedder P (2018) Variability in Developmental Outcomes of Foster Children: Implications for Research and Practice. Children Australia 43(2): 116-123. Hambrick EP, Brawner TW and Perry BD (2018) Examining Developmental Adversity and Connectedness in Child Welfare-Involved Children. Children Australia 43(2): 105-115. 
Helm D and Roesch-March A (2017) The Ecology of Judgement: A Model for Understanding and Improving Social Work Judgements. British Journal of Social Work 47: 1361-1376.

Keddell E (2014) Current Debates on Variability in Child Welfare Decision-Making: A Selected Literature Review. Social Sciences 3: 916-940.

Linhorst DM (2002) A review of the use and potential of focus groups in social work research. Qualitative Social Work 1(2): 208-28.

Lloyd EC and Barth R P (2011) Developmental outcomes after five years for foster children returned home, remaining in care, or adopted. Children and Youth Services Review 33(8): $1383-1391$

Luke N and O'Higgins A (2018) Is the Care System to Blame for the Poor Educational Outcomes of Children Looked After? Evidence from a Systematic Review and National Database Analysis. Children Australia 43(2): 135-151.

McClung M and Gayle V (2010) Exploring the care effects of multiple factors on the educational achievement of children looked after at home and away from home: an investigation of two Scottish local authorities. Child and Family Social Work 15(4): 409-431. McSherry D, Weatherall K and Fargas Malet M (2010) Who goes where? Young children's pathways through care in Northern Ireland. Adoption and Fostering Journal 34(2): 23-37.

McSherry D, Fargas Malet, M and Weatherall, K (2013) Comparing long-term placements for young children in care: The care pathways and outcomes study - Northern Ireland. London: British Association for Adoption and Fostering.

McSherry, D, Fargas Malet, M, McLaughlin, K, Adams, C, O’Neill, N, Cole, J and Walsh, C (2015) Mind Your Health: The physical and mental health of looked after children and young people in Northern Ireland. Belfast: Queen's University Belfast. 
McSherry, D, Fargas Malet, M and Weatherall, K (2016) Comparing long-term placements for young children in care: Does type of placement really matter? Children and Youth Services Review 69: 56-66.

O'Connor L and Leonard K (2013) Decision making in children and families social work: The practitioner's voice. British Journal of Social Work 44(7): 1805-1822.

Oliver C, Owen C., Statham J and Moss P (2001) Figures and facts: Local authority variance on indicators concerning child protection and children looked after. London: Thomas Coram Research Unit, University of London, Institute of Education.

Packman J and Hall C (1998) From care to accommodation: Support, protection and control in child care services. London: The Stationary Office.

Ritchie J and Spencer L (1994) Qualitative data analysis for applied policy research. In: Bryman A and Burgess RG (eds) Analyzing qualitative data. London: Routledge, pp.173194.

Rock S, Michelson D, Thomson S and Day C (2015) Understanding foster placement instability for looked after children: A systematic review and narrative synthesis of quantitative and qualitative evidence. British Journal of Social Work, 45(1): 177-203.

Statham J, Candappa M, Simon A and Owen C (2002) Trends in care: Exploring the reasons for the increase in children looked after by local authorities. London: Thomas Coram Research Unit, University of London, Institute of Education.

Stott T and Gustavsson N (2010) Balancing permanency and stability for youth in foster care. Children and Youth Services Review 32: 619-625.

Taylor BJ (2012) Models for professional judgement in social work. European Journal of Social Work 16(4): 646-662.

Taylor BJ (2017) Heuristics in Professional Judgement: A Psycho-Social Rationality Model. British Journal of Social Work 47: 1043-1060. 
Van de Luitgaarden GMJ (2009) Evidence-Based Practice in Social Work: Lessons from Judgement and Decision-Making Theory. British Journal of Social Work 39: 243-260.

Vinnerljung B and Hjern A (2011) Cognitive, educational and self-support outcomes of longterm foster care versus adoption. A Swedish national cohort study. Children and Youth Services Review 33(10): 1902-1910.

Ward H, Munro EH and Deardon C (2006) Babies and Young Children in Care: Life pathways, decision-making and practice. London: Jessica Kingsley Publishers.

Winokur MA, Holtan A and Batchelder KE (2015) Systematic Review of Kinship Care Effects on Safety, Permanency, and Well-Being Outcomes. Research on Social Work Practice 28(1): 19-32. 